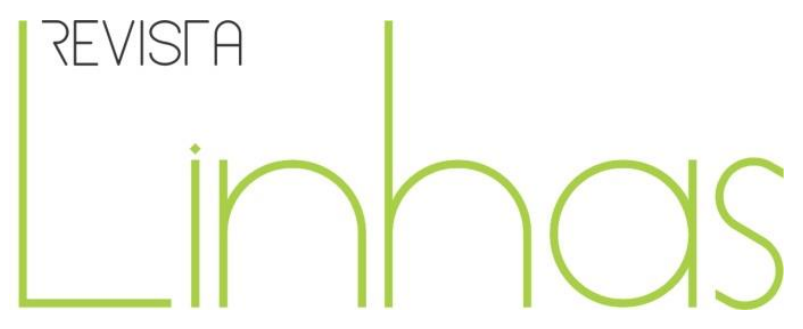

\title{
Ilusão biográfica: a polêmica sobre o valor das histórias de vida na sociologia de Pierre Bourdieu
}

\begin{abstract}
Resumo
Este ensaio visa problematizar a polêmica crítica dirigida à noção de história de vida com base na análise de uma edição da revista Actes de la recherche en sciences sociales, publicada em 1986 e que tem como título A ilusão biográfica. Percorre os 13 textos que compõem a edição para esclarecer a suposta aversão do sociólogo francês Pierre Bourdieu pelas histórias de vida, considerando-as como resultado de leituras superficiais de sua crítica e do desconhecimento das demais contribuições que compõem a edição. Aponta que o conjunto dos trabalhos não permite que o título da edição seja transformado em pecha e sintetiza as principais ideias presentes nos textos, as quais servem como recomendações metodológicas para as ciências humanas e sociais em geral, na expectativa de que tais ideias facilitem a compreensão sobre a crítica bourdieusiana à descrição finalista, tão comum nas histórias de vida, e por ele aprofundada em algumas partes dos livros As regras da arte e Meditações pascalianas. Conclui que a noção de trajetória, livre da ilusão retrospectiva e da ideologia do dom e da predestinação, merece especial atenção em pesquisas autobiográficas, como alternativa de apreensão dos sentidos atribuídos às experiências relatadas pelos agentes sociais que tomamos como sujeitos de nossas investigações.
\end{abstract}

Palavras-chave: Ilusão biográfica; Histórias de vida; Problemas teórico-metodológicos; Trajetória.
Patrícia Claudia da Costa

Doutoranda em Educação pela

Faculdade de Educação da

Universidade de São Paulo -

FEUSP - Brasil

patriciaclaudia@usp.br

\section{Para citar este artigo:}

COSTA, Patrícia Claudia da. Ilusão biográfica: a polêmica sobre o valor das histórias de vida na sociologia de Pierre Bourdieu. Revista Linhas. Florianópolis, v. 16, n. 32, p. 51 - 71, set./dez. 2015. 


\title{
Biographical illusion: the controversy valour of life histories in the sociology of Pierre Bourdieu
}

\begin{abstract}
This essay aims to problematize the controversy critics to the notion of life histories, based on the analyze of an edition of the review Actes de la recherche en sciences sociales, published in 1986 and whose title is The biographical illusion. It covers all the texts that compose the edition to clarify the supposed aversion to life histories, commonly attributed to the French sociologist Pierre Bourdieu, as well it considers that state as a result of superficial readings and unknowledge about the others contributions that compose the edition. It shows that the title has been improperly misunderstood and it summarizes the main ideas of the texts, which can be used as methodological advices for the human and social sciences in general. It hopes that such ideas improve the comprehension about the bourdieusian critics to the finalist description, very common in the life histories, and it shows his effort for making a deeper reflection in some parts of the books The rules of the art and Pascalian meditations. It concludes that the notion of trajectory, free of the retrospective illusion and the ideology of the gift and the predestination, calls for special attention in the autobiographical researches as alternative to apprehend the meanings attributed to the experiences by part of the social agents that we take as subjects of our investigations.
\end{abstract}

Keywords: Biographical illusion; Life histories; Theoretical-methodological problems; Trajectory. 
O campo acadêmico é um espaço no qual as ideias são objeto de disputa e, ao mesmo tempo, armas dessa disputa. Algumas ideias são sólidas o bastante para sustentar paradigmas, correntes, teorias e uma infinidade de perpetuadores. Outras são apenas pontos de inflexão de uma teoria e servem para discutir fundamentos e apropriações. Ainda há aquelas que traduzem tão somente tentativas de construir novos conhecimentos ou novas formas de compreender o já conhecido, algumas das quais nem sempre exitosas. Todas se prestam, no entanto, às disputas travadas por meio de pesquisas e seus produtos, discutidos em livros, artigos, aulas, orientações de teses, grupos de pesquisa, eventos científicos e, até mesmo, em conversas informais pelos corredores e demais pontos de encontro dos agentes sociais que disputam nesse campo.

Este trabalho pretende discutir uma ideia que pode ser considerada um controverso ponto de inflexão da teoria bourdieusiana, quando se faz uma leitura descontextualizada. Trata-se da noção de ilusão biográfica, difundida a partir do título de uma edição da revista Actes de la recherche en sciences sociales (doravante Actes), que continha artigo homônimo, assinado por Pierre Bourdieu, ao lado de outros doze trabalhos.

Na tentativa de apresentar elementos que contribuam para o esclarecimento da falsa polêmica em torno do valor das histórias de vida na sociologia de Pierre Bourdieu, este texto está organizado nas seguintes seções: apresentação da revista Actes, estrutura e conteúdos do volume L'illusion biographique, principais aportes apresentados neste volume para a problematização de metodologias que recorrem a fontes biográficas, recorrência do problema em escritos de Pierre Bourdieu e, finalmente, o que podemos apreender sobre o uso de material de natureza biográfica, mediante a análise do conjunto dos trabalhos veiculados nessa edição específica.

\section{Actes}

A revista se define como um periódico que "seleciona a produção de uma vasta rede internacional de pesquisadores em ciências humanas e sociais, na perspectiva de uma sociologia crítica dos modos de dominação". Fundada, em 1975, por Pierre Bourdieu e um grupo de colaboradores vinculados ao Centro Europeu de Sociologia, o veículo tem 
mantido a tradição de cadernos temáticos trimestrais que publicam, além de artigos, notas de pesquisa, relatórios de campo em sociologia e disciplinas afins, dicas de leitura e resenhas. A observação dos títulos e sumários das edições, ao longo de sua existência, revela a diversidade de questões presentes na revista, considerada uma das mais prestigiadas internacionalmente em sua área, em versão online e impressa.

O periódico contou com o prestígio acadêmico de Pierre Bourdieu no comando editorial até sua morte, em 2002, quando a direção das publicações foi assumida por Jérôme Bourdieu, professor da Escola de Economia de Paris, auxiliado por uma grande rede internacional de colaboradores, muitos deles alinhados, há décadas, aos trabalhos desenvolvidos por seu pai.

Para contextualizar a edição de junho de 1986, correspondente aos volumes 62 e 63, intulada L'illusion biographique, vale lembrar que a revista já estava em seu décimo primeiro ano de existência e gozava de relativa importância no cenário acadêmico da época. Além disso, seu editor, autor do texto que dá nome à edição, acumulava, até então, considerável experiência como etnólogo e sociólogo, expressa em 18 livros e dezenas de artigos. O conjunto de sua produção entre 1958 e 1986 atesta sua maturidade, na qual se destaca a preocupação com as questões epistemológicas e metodológicas do trabalho científico ${ }^{1}$.

\section{A edição L’illusion biographique}

Publicada em junho de 1986, a edição L'illusion biographique contém 13 textos ${ }^{2}$, de extensões que variam entre quatro e 29 páginas, uma seção de sugestões de leitura e uma de sumário de números precedentes. Assim como na maioria das edições da Actes, não há texto de editorial, introdução ou prefácio, o que facilitaria nossa análise do propósito da temática. Na impossibilidade de apresentar resumos e discutir os conteúdos de cada um desses trabalhos, foi elaborado um quadro que expõe sumariamente, e na

\footnotetext{
${ }^{1}$ Os livros Ofício de sociólogo: preâmbulos epistemológicos e O senso prático, publicados originalmente em 1968 e 1980 expressam sua reflexão sobre a necessidade de constante vigilância epistemológica para se produzir conhecimento científico na perspectiva de um pensamento relacional que supere a dicotomia objetivismo-subjetivismo pela objetivação do sujeito objetivante.

${ }^{2}$ Todas as traduções de títulos e textos são de responsabilidade da autora.
} 
sequência de publicação, os títulos com os respectivos autores, tema do artigo, problema central e metodologia utilizada.

Textos que compõem a edição L'illusion biographique

\begin{tabular}{|c|c|c|c|}
\hline Artigo e autor & Tema & Problema & Metodologia \\
\hline $\begin{array}{l}\text { Le témoignage } \\
\text { (O depoimento) } \\
\text { Michael Pollak } \\
\text { Nathalie Heinich }\end{array}$ & $\begin{array}{l}\text { Experiência } \\
\text { extrema } \\
\text { tomada como } \\
\text { um revelador } \\
\text { da identidade } \\
\text { como imagem } \\
\text { de si para si e } \\
\text { para os outros. }\end{array}$ & $\begin{array}{l}\text { Diferentes tipos de } \\
\text { depoimentos (judiciário, } \\
\text { político e científico) de } \\
\text { sobreviventes do campo de } \\
\text { Auschwitz-Birkenau } \\
\text { implicam num conteúdo } \\
\text { diferente quanto ao que é } \\
\text { relatado e um sentido } \\
\text { diferente quanto à sua } \\
\text { função. }\end{array}$ & $\begin{array}{l}\text { Projeto de história oral, com } \\
\text { características } \\
\text { autobiográficas e corpus } \\
\text { constituído por escritos } \\
\text { autobiográficos ou relatos de } \\
\text { vida, recolhidos por } \\
\text { entrevista, } 40 \text { anos após a } \\
\text { experiência. }\end{array}$ \\
\hline $\begin{array}{l}\text { La gestion de } \\
\text { l'indicible } \\
\text { (A gestão do } \\
\text { indizível) } \\
\text { Michael Pollak }\end{array}$ & $\begin{array}{l}\text { Mulheres que } \\
\text { sobreviveram a } \\
\text { um campo de } \\
\text { concentração. }\end{array}$ & $\begin{array}{l}\text { Até que ponto o silêncio é } \\
\text { assimilado como } \\
\text { esquecimento? }\end{array}$ & Entrevista de história de vida. \\
\hline $\begin{array}{l}\text { Contribution à la } \\
\text { sociologie de la } \\
\text { confession et } \\
\text { autres formes } \\
\text { institutionnalisée } \\
\text { s d'aveu } \\
\text { Contribuição à } \\
\text { sociologia da } \\
\text { confissão e } \\
\text { outras formas } \\
\text { institucionalizada } \\
\text { s } \\
\text { de testemunho } \\
\text { (Aloïs Hahn, } \\
\text { traduzido do } \\
\text { alemão por } \\
\text { Robert Guého) }\end{array}$ & $\begin{array}{l}\text { Confissão } \\
\text { como } \\
\text { autodescobert } \\
\text { a e exame da } \\
\text { vida como um } \\
\text { todo. }\end{array}$ & $\begin{array}{l}\text { Mudanças nas formas de } \\
\text { confissão desde o século XII } \\
\text { relacionadas à instituição do } \\
\text { sacramento da penitência, à } \\
\text { interiorização e à } \\
\text { subjetivação da } \\
\text { culpabilidade ao mesmo } \\
\text { tempo em que desenvolvem } \\
\text { e intensificam o } \\
\text { autocontrole. }\end{array}$ & $\begin{array}{l}\text { Historicização da confissão } \\
\text { desde o século XII. } \\
\text { Não se trata de uma pesquisa } \\
\text { biográfica, mas da discussão } \\
\text { de um tema que repercute } \\
\text { em questões biográficas. }\end{array}$ \\
\hline $\begin{array}{l}\text { L'illusion } \\
\text { biographique } \\
\text { A ilusão } \\
\text { biográfica } \\
\text { (Pierre Bourdieu) }\end{array}$ & $\begin{array}{l}\text { Os perigos do } \\
\text { uso de material } \\
\text { biográfico } \\
\text { como fonte de } \\
\text { pesquisa. }\end{array}$ & $\begin{array}{l}\text { Relatos biográficos } \\
\text { incorrem em ilusão } \\
\text { retrospectiva, } \\
\text { ingenuamente finalista, e } \\
\text { atribuem causalidades que } \\
\text { nem sempre correspondem } \\
\text { às trajetórias reais dos } \\
\text { agentes sociais. }\end{array}$ & Ensaio teórico. \\
\hline
\end{tabular}




\begin{tabular}{|c|c|c|c|}
\hline $\begin{array}{l}\text { Fils de Pasteur } \\
\text { Filhos de pastor } \\
\text { (Pierre Pénisson) }\end{array}$ & $\begin{array}{l}\text { Características } \\
\text { de filhos de } \\
\text { pastores que } \\
\text { nasceram } \\
\text { depois da II } \\
\text { Guerra } \\
\text { Mundial. }\end{array}$ & $\begin{array}{l}\text { Modificações de } \\
\text { comportamento em sujeitos } \\
\text { que não seguiram a vida } \\
\text { sacerdotal que compunha o } \\
\text { seu universo infantil. }\end{array}$ & $\begin{array}{l}\text { Entrevistas de filhos caçulas } \\
\text { de pastores, entre } 30 \text { e } 40 \\
\text { anos, que tiveram infância } \\
\text { em casa paroquial e que hoje } \\
\text { não têm atividade religiosa. } \\
\text { Faz indicações biográficas } \\
\text { dos } 12 \text { sujeitos mais citados: } \\
\text { origem paterna e materna, } \\
\text { atividade econômica da } \\
\text { família, onde viveu a infância, } \\
\text { fratraria, estudos e profissão. }\end{array}$ \\
\hline $\begin{array}{l}\text { Fils de pasteur ou } \\
\text { enfants de } \\
\text { pasteur(s) } \\
\text { Filhos de pastor } \\
\text { ou enfants } \\
\text { [criança sem } \\
\text { distinção de } \\
\text { gênero] de } \\
\text { pastor(es) } \\
\text { (Pierre Encrevé) }\end{array}$ & $\begin{array}{l}\text { habitus } \\
\text { parental } \\
\text { exposto no } \\
\text { artigo de Pierre } \\
\text { Pénisson. }\end{array}$ & $\begin{array}{l}\text { No período atual, os } \\
\text { meninos que são filhos de } \\
\text { pastores não partilham o } \\
\text { mesmo habitus } \\
\text { específico de crianças que } \\
\text { se enquadram na categoria } \\
\text { de filhos de pastor? }\end{array}$ & $\begin{array}{l}\text { Expõe dados estatísticos } \\
\text { para criticar a impossibilidade } \\
\text { de generalizar os resultados } \\
\text { obtidos pelo estudo } \\
\text { discutido no artigo de } \\
\text { Pénisson, que só é válido } \\
\text { para o grupo de } 12 \text { sujeitos } \\
\text { investigados. }\end{array}$ \\
\hline $\begin{array}{l}\text { La vie militante } \\
\text { d'un peintre en } \\
\text { lettres: I'ideologie } \\
\text { contre } \\
\text { l'entreprise } \\
\text { A vida militante } \\
\text { de um pintor de } \\
\text { letreiros: a } \\
\text { ideologia contra } \\
\text { a empresa } \\
\text { (Bernard Zarca) }\end{array}$ & $\begin{array}{l}\text { A vida de um } \\
\text { artesão, filho } \\
\text { de pintor de } \\
\text { carros; } \\
\text { pequeno } \\
\text { burguês, que } \\
\text { adere ao } \\
\text { partido } \\
\text { comunista. }\end{array}$ & $\begin{array}{l}\text { Como um artesão militante } \\
\text { vê o capitalismo e se insere } \\
\text { na lógica do mundo do } \\
\text { trabalho, de "ter que } \\
\text { ganhar a vida". }\end{array}$ & $\begin{array}{l}\text { Intercala trechos de } \\
\text { depoimento com análise da } \\
\text { trajetória relatada. } \\
\text { Não há problematização ou } \\
\text { explicitação da metodologia. }\end{array}$ \\
\hline $\begin{array}{l}\text { Un ouvrier } \\
\text { désenchanté } \\
\text { Um operário } \\
\text { desencantado } \\
\text { (Michel Pinçon } \\
\text { Paul Rendu) }\end{array}$ & $\begin{array}{l}\text { Desencanto } \\
\text { profissional de } \\
\text { um moldador } \\
\text { frente às novas } \\
\text { condições e } \\
\text { relações de } \\
\text { trabalho. }\end{array}$ & $\begin{array}{l}\text { A racionalização da } \\
\text { produção, o processo de } \\
\text { desqualificação e a perda de } \\
\text { elementos da autonomia } \\
\text { que autorizava a maestria } \\
\text { do saber-fazer, hoje } \\
\text { desvalorizados; introduzem } \\
\text { progressivamente uma } \\
\text { profunda discordância entre } \\
\text { o operário e o que se tornou } \\
\text { seu trabalho na fundição. }\end{array}$ & $\begin{array}{l}\text { Longos excertos de } \\
\text { depoimento de um operário } \\
\text { (não informa se coletado em } \\
\text { entrevista) sem discussão } \\
\text { quanto aos aspectos } \\
\text { metodológicos. }\end{array}$ \\
\hline
\end{tabular}




\begin{tabular}{|c|c|c|c|}
\hline $\begin{array}{l}\text { Le paradis perdu } \\
\text { O paraíso } \\
\text { perdido } \\
\text { (Patrice Pinell) }\end{array}$ & Toxicomania. & $\begin{array}{l}\text { As vinculações entre } \\
\text { diferentes maneiras de } \\
\text { consumir drogas e de se } \\
\text { situar no meio underground, } \\
\text { e os problemas sociais } \\
\text { enfrentados pelos narrador. }\end{array}$ & $\begin{array}{l}\text { Entrevista com um sujeito } \\
\text { que frequenta um centro } \\
\text { para tratamento de } \\
\text { toxicômanos. } \\
\text { Longos excertos e poucas } \\
\text { análises, sem discussão sobre } \\
\text { os aspectos metodológicos. }\end{array}$ \\
\hline $\begin{array}{l}\text { Biographie et } \\
\text { mosaïque } \\
\text { scientifique } \\
\text { Biografia e } \\
\text { mosaico } \\
\text { científico } \\
\text { (Howard Becker, } \\
\text { traduzido do } \\
\text { inglês por } \\
\text { Suzanne e Jean } \\
\text { Peneff) }\end{array}$ & $\begin{array}{l}\text { O uso de } \\
\text { material } \\
\text { biográfico } \\
\text { como fonte de } \\
\text { pesquisa. }\end{array}$ & $\begin{array}{l}\text { O lugar do método } \\
\text { biográfico na sociologia } \\
\text { contemporânea. }\end{array}$ & $\begin{array}{l}\text { Ensaio introdutório do livro } \\
\text { The Jack-Roller, de Clifford R. } \\
\text { Shaw, originalmente } \\
\text { publicado em } 1966 \text { pela } \\
\text { editora da Universidade de } \\
\text { Chicago. }\end{array}$ \\
\hline $\begin{array}{l}\text { In memoriam } \\
\text { Em memória } \\
\text { (François } \\
\text { Carlotti) }\end{array}$ & $\begin{array}{l}\text { Um olhar } \\
\text { particular } \\
\text { sobre a história } \\
\text { da França. }\end{array}$ & $\begin{array}{l}\text { Como uma visão francesa da } \\
\text { história da França marcada, } \\
\text { sobretudo, pelo choque da } \\
\text { Grande Guerre, pode se } \\
\text { tornar tão importante } \\
\text { quanto os eventos por si } \\
\text { mesmos. }\end{array}$ & $\begin{array}{l}\text { Publicação integral de duas } \\
\text { cartas, datadas em 1974, sem } \\
\text { análise e com pequeno } \\
\text { preâmbulo de apresentação } \\
\text { e justificação da importância } \\
\text { de divulgar o material. }\end{array}$ \\
\hline $\begin{array}{l}\text { Un conseil de } \\
\text { classe très } \\
\text { particulier } \\
\text { Um conselho de } \\
\text { classe muito } \\
\text { particular } \\
\text { (Gabrielle Balazs } \\
\text { Jean-Pierre } \\
\text { Faguer) }\end{array}$ & $\begin{array}{l}\text { O destino de } \\
\text { estudantes } \\
\text { determinado } \\
\text { por um } \\
\text { conselho de } \\
\text { classe. }\end{array}$ & $\begin{array}{l}\text { O funcionamento de uma } \\
\text { comissão que define o } \\
\text { destino escolar de } \\
\text { estudantes com defasagem } \\
\text { de aprendizagem. }\end{array}$ & $\begin{array}{l}\text { Os pesquisadores assistiram } \\
\text { a uma reunião da comissão e } \\
\text { anotaram o que foi possível; } \\
\text { meses depois, retornaram à } \\
\text { instituição para colher } \\
\text { informações atualizadas } \\
\text { sobre os casos discutidos } \\
\text { pelo conselho. } \\
\text { Indicações biográficas } \\
\text { restritas às informações } \\
\text { citadas na reunião (nome, } \\
\text { idade e problema escolar). } \\
\text { Sem discussão dos aspectos } \\
\text { metodológicos. }\end{array}$ \\
\hline $\begin{array}{l}\text { Réincarnations: } \\
\text { note de recherche } \\
\text { sur une secte } \\
\text { spirite de Brasilia } \\
\text { Reencarnações: } \\
\text { notas de } \\
\text { pesquisa sobre }\end{array}$ & $\begin{array}{l}\text { Comunidade } \\
\text { religiosa (seita } \\
\text { espírita) em } \\
\text { Brasília, Vale } \\
\text { do Amanhecer. }\end{array}$ & $\begin{array}{l}\text { Aspectos da trajetória social } \\
\text { e religiosa de líderes da } \\
\text { seita e traços originais do } \\
\text { ritual e da doutrina parecem } \\
\text { estar no princípio do } \\
\text { sucesso social do Vale, a } \\
\text { ponto de propor hipóteses } \\
\text { de trabalho para uma }\end{array}$ & $\begin{array}{l}\text { Abordagem descritiva de } \\
\text { características das } \\
\text { trajetórias sociais e de } \\
\text { experiências místicas dos } \\
\text { dirigentes da seita, } \\
\text { relacionadas analiticamente } \\
\text { com questões histórica e } \\
\text { sociais que, por sua vez, se }\end{array}$ \\
\hline
\end{tabular}




\begin{tabular}{|l|l|l|l|}
\hline uma seita espírita & sociologia da adesão. & relacionam com o mundo \\
de Brasília & & & \\
(Francine Muel- & & & \\
Dreyfus & & \\
Arakcy Martins & & & \\
Rodrigues) & & & \\
\hline
\end{tabular}

Como pode ser observado nas sumárias informações sobre cada um dos textos que compõem a edição L'illusion biographique, a controversa expressão abarca um conjunto de trabalhos que problematizam, criticam, refletem sobre e, majoritariamente, fazem uso de material biográfico como fonte de pesquisa. Portanto, um primeiro e crucial ponto a ser compreendido, quando se considera a integralidade da edição, diz respeito à inexistência de recusa ou de desprestígio das fontes (auto)biográficas pelos autores desses trabalhos. Embora a maioria dos textos não contenha ponderações explícitas sobre a metodologia utilizada, todos têm em comum o potencial de dar visibilidade aos limites e possibilidades de uso desse tipo de fonte de pesquisa. Alguns trabalham com relatos biográficos de apenas um sujeito, outros utilizam entrevistas com grupos de indivíduos caracterizados como pertinentes para ilustrar o problema investigado. Há ainda dois casos de textos que se dedicam a analisar outros trabalhos da mesma edição, como nos dois primeiros artigos (inclusive redigidos pelo mesmo autor) e os estudos sobre filhos de pastores que discutem um fenômeno social controverso e problematizam a eficácia da generalização em estudos qualitativos com universos insuficientemente representativos.

Deixando de lado os textos que não oferecem elementos para discussão da reflexividade de seus autores sobre a opção metodológica adotada, vejamos as contribuições mais relevantes para a problematização do uso das histórias de vida, das (auto)biografias, das entrevistas que recolhem relatos de vida, enfim, das estratégias metodológicas que empregam fontes biográficas para a produção de conhecimento científico. 


\section{Principais aportes para a discussão sobre fontes biográficas}

Do total de 13 textos, podemos concluir que apenas quatro deles refletem, explicitamente, sobre a ideia central que pretendemos discutir. São eles: "O depoimento", de Michel Pollack e Nathalie Heinich; "A gestão do indizível”, de Michel Pollack; "Biografia e mosaico científico", de Howard Becker; e, como não poderia deixar de ser, "A ilusão biográfica", de Pierre Bourdieu. Os demais, ainda que relacionados à problemática, não acrescentam grandes questões para a discussão específica sobre a metodologia de pesquisa.

No primeiro texto, são identificados três tipos de discursos recorrentes em relatos de vida (judiciário, político e científico) e já se prenuncia que o silêncio, tema do trabalho seguinte, "diferente do esquecimento, pode ser escolhido como um modo de gestão da identidade segundo as possibilidades de comunicação dessa experiência extrema" (POLLACK; HEINICH, 1986, p. 05). Defende-se que todo depoimento se situa num "espaço do dizível", responsável por deformações e obscuridades que caracterizam alguns relatos sobre situações extremas. O artigo discute que a análise desse tipo de experiência permite explicitar como a amostra, o método e o objeto analisado se condicionam reciprocamente: se, desses três elementos constitutivos de uma construção científica, apenas um varia, os outros dois variam também.

Pollack e Heinich não deixam dúvidas quanto ao estatuto privilegiado da abordagem biográfica como instrumento de investigação, principalmente quando se trata de objetos relacionados à reconstrução da identidade, que não se bastam com relatos factuais e limitados a uma função informativa. Com igual rigor, apontam o problema da veracidade das fontes. Sugerem uma análise que integre tudo o que é expresso pelo material disponível ao contexto de sua produção e de seus destinatários (presumidos e reais), de maneira que se estabeleça um intercâmbio permanente entre os materiais empíricos e a construção teórica. Em outras palavras, a análise deve tomar, de forma indissociável, os fatos relatados, a posição do narrador e suas ligações com os destinatários, pois há coisas que não podem ser ditas em determinados contextos.

De acordo com os autores, a metodologia autobiográfica se caracteriza como um espaço discursivo que permite a reconstituição de uma pluralidade de vozes que se 
exprimem, permitindo o entendimento dos fatos sem que haja necessidade de passagem do registro individual e singular para um registro geral. Esse espaço depende de um trabalho de negociação e de compromisso para que se tenha acesso à ordem mental, responsável pela gestão da identidade, de modo a interpretar as experiências coerentemente, integrando o presente ao passado. Além disso, observa-se que os documentos resultam do encontro entre a disposição do sobrevivente em falar e as oportunidades de ser escutado, num clima de reconstrução da experiência biográfica.

No texto "A gestão do indizível”, Pollack aprofunda a ideia segundo a qual a análise dos relatos de vida sugere que sejam considerados como uma possibilidade de reconstrução de identidade e não somente como um relato factual. Por isso, insiste na necessidade de estabelecimento de uma relação de confiança entre pesquisador e pesquisado como garantia de êxito no recolhimento de uma vida, bem como no fato de que, encarada sociologicamente, uma biografia não fala por si própria conforme assumimos que o trabalho de pesquisa consiste fundamentalmente da tentativa de esboçar constantes, sociologicamente produzidas, da variação quase infinita das histórias sociais individuais que definem um grupo dado. Portanto, a sociologia de um conjunto construído de histórias de vida é inseparavelmente uma análise histórica que revela que as histórias e as memórias vinculam-se aos locais de sua produção e ao público para o qual se destinam. Os relatos refletem, assim, a constituição de uma identidade social que se diferencia tal como observado alhures por Bourdieu (neste ponto, Pollack se refere à primeira edição do livro La Distinction, publicado em Paris, pela Éditions de Minuit, em 1979). Seguindo a argumentação de Pollack:

Um passado que permanece em silêncio é, talvez, menos o produto do esquecimento do que uma gestão da memória segundo as possibilidades de comunicação em tal ou qual momento da vida. Essa gestão da memória não rege somente o que é dito em diferentes momentos da vida. [...] Nós tentamos agir conforme os contextos nos quais nos expressamos, como modificamos o que dizemos em função da variação dos contextos. Assim, toda a vida social atual de Ruth pode parecer, a uma só vez, como o resultado e o reflexo de um modo de gestão da memória. (POLLACK, 1986, p. 51) 
Nessa perspectiva, o relato de vida pode ser considerado como o condensado de uma história social individual, suscetível de múltiplos modos de exposição em função do contexto em que esteja inserido. A variação é restrita, não ilimitada, o que permite, ainda assim, que cada sujeito tenha a experiência de variar o relato de uma parte de sua vida, enfatizando algum aspecto ou alterando-lhe o sentido. É como se encarássemos cientificamente o fato, observado no cotidiano, de que nunca contamos a mesma história do mesmo modo para duas pessoas diferentes em dois momentos e lugares distintos. Dessa maneira, a história de vida é vista, por definição, como uma reconstrução $a$ posteriori, um relato que ordena os eventos que marcaram uma vida. Ademais, ao recontar uma vida, busca-se, geralmente, estabelecer alguma coerência entre os acontecimentos mais significativos e uma continuidade cronológica, como se coerência e continuidade assegurassem uma identidade.

O terceiro texto a ser destacado é o de Howard Becker, "Biografia e mosaico científico", que propõe uma reflexão sobre o lugar do método biográfico na sociologia contemporânea. Escrito originalmente em inglês, vale informar o alerta dos tradutores sobre a opção de usar biographie para a expressão life history, por julgarem que as expressões histoire de vie ou récit de vie não parecem ser suficientes para incluir a responsabilidade do sociólogo na condução da pesquisa sobre um destino individual. Assim, o termo biographie expressa melhor a ideia de que o trabalho sociológico não se encerra apenas com o material fornecido pelo sujeito investigado, mas abarca dados externos e depoimentos de outros indivíduos sobre ele, o que distingue a biografia de um simples relato ou da autobiografia.

\begin{abstract}
A biografia não é um "material" ordinário nas ciências sociais. [...] Não se deve assimilá-la à autobiografia clássica, ainda que compartilhe com ela a forma narrativa, o discurso em primeira pessoa e um ponto de vista subjetivo. Não se pode comparar ao romance, apesar de os melhores documentos biográficos comportarem uma sensibilidade, um ritmo, uma tensão dramática que nem todo romancista exprimiria tão bem. (BECKER, 1986, p. 105)
\end{abstract}

Para o autor, diferenciar biografia de romance ajuda a esclarecer o seu uso científico. Em linhas gerais, o romancista não se preocupa com os fatos em si, mas com o 
impacto emocional e dramático, com as formas e imagens, com a criação de um universo simbólico dotado de uma unidade estética, sem necessidade de ser fiel à realidade. Já o autobiógrafo reconta sua vida buscando manter uma coerência entre a história narrada e tudo que uma investigação poderia descobrir, escolhendo os fatos que representam aquilo que interessa ao investigador. A prática biográfica ${ }^{3}$, por sua vez, é mais prosaica e se submete mais aos objetivos do sociólogo que aos do seu narrador, menos preocupada com o valor artístico do produto final que com a restituição fiel da experiência do sujeito e sua interpretação do mundo em que vive.

Com essas diferenciações em mente, Becker(1986) afirma que o sociólogo que trabalha com biografia deve assegurar que coletou informações sobre todos os acontecimentos importantes e que os fatos são passíveis de confirmação por outros depoimentos, além da interpretação oferecida pelo próprio narrador. Por isso, a entrevista deve ser guiada conforme os temas que the interessam e buscando a comprovação dos acontecimentos narrados. Apenas a rigorosidade metódica do pesquisador pode assegurar um resultado de pesquisa adequado.

A metáfora presente no título do texto, mosaico científico, ilustra o pensamento de Becker ao distinguir os trabalhos sociológicos. Para o autor, a figura do mosaico nos dá a perfeita dimensão de um trabalho que se torna cada vez mais rico, quanto mais peças são nele encaixadas. Cada peça contribui para a compreensão do quadro, apesar de nem todas terem a mesma importância na composição da figura, do mesmo modo que biografias de diferentes indivíduos terão diferentes pesos na comprovação ou refutação de uma determinada teoria sociológica. No mosaico, há peças que são importantes no preenchimento da figura, algumas na definição do contorno, outras estão ali apenas para compor o fundo da imagem. O conjunto das peças forma o todo que deve ser visto. $O$ mesmo se dá no trabalho científico que utiliza material biográfico ao construir mosaicos de explicação de uma dada realidade social juntando estudos particulares ou tomando um caso representativo como "pedra de toque" para julgar o valor de uma teoria,

\footnotetext{
${ }^{3}$ Como exemplo da tradição no uso de biografias em investigações sociológicas, fala de alguns trabalhos desenvolvidos pela Universidade de Chicago, desde os anos de 1920, fundamentados na psicologia social de Georges Herbert Mead.
} 
inclusive quando se faz o exame de um "caso negativo", ou seja, um caso particular que não se adéqua a uma teoria que lhe precede.

A biografia, portanto, "assim como outros tipos de informação, fornece uma base para fundar as hipóteses numa realidade e uma indicação aproximativa da direção na qual se encontra a verdade" (BECKER, 1986, p. 108). Quando bem feita, revela detalhes do processo de socialização ao descrever as principais sequências de interação nas quais novas vias de ação coletiva e individuais são forjadas e novos aspectos da personalidade emergem. Sua riqueza de detalhes permite a análise de muitas variáveis com grande precisão, o que pode levar o pesquisador, inclusive, a reorientar o sentido da investigação quando novos processos, questões e variáveis são revelados, na medida em que a biografia permite verificar as hipóteses e esclarecer a organização da pesquisa.

A preocupação dos sociólogos com o desenvolvimento da teoria abstrata é apontada por Becker como um dos fatores do declínio do método biográfico, pois eles priorizam as categorias abstratas de suas próprias teorias, em detrimento daquilo que parece ser mais relevante para os grupos estudados. Outro fator de declínio é a distinção entre psicologia social e sociologia propriamente dita, que cria "duas especialidades ao invés de duas orientações num mesmo domínio", priorizando as variáveis estruturais. 0 maior problema, contudo, é o fato

[...] dessa técnica, talvez, não produzir o tipo de 'resultados' que os sociólogos esperam de uma pesquisa hoje em dia. À medida que a sociologia se institucionalizou e se 'profissionalizou', a ênfase é colocada, mais e mais, no que podemos chamar, para simplificar, de estudo isolado (single study). (BECKER, 1986, p. 209, aspas do autor)

O autor ilustra o "estudo isolado" com uma metáfora oposta a do mosaico. Ele pensa os estudos autônomos e independentes como tijolos (provas) num muro (teoria). Eles fornecem todos os elementos de prova necessários para aceitar ou rejeitar as conclusões do muro da ciência, integrando o corpo do conhecimento de modo a formular hipóteses a partir do já conhecido. Quando a pesquisa confirma o que já se sabe, une-se ao muro (aquilo que já é cientificamente conhecido) e será usada como base para pesquisas futuras. É como se as hipóteses fossem confirmadas ou invalidadas a partir do 
que se descobre ao longo de uma parcela (tijolo) da pesquisa (muro), com critérios do modelo experimental que podem ter "consequências nefastas" quando levam os sociólogos a negligenciar outras funções do trabalho científico, principalmente reconhecer a contribuição de um trabalho para um projeto de pesquisa global, mesmo quando seu estudo não produz, particularmente, resultados decisivos. Como sabemos, o método biográfico não produz resultados definitivos e essa é uma das razões pelas quais alguns pesquisadores se recusam a adotá-lo.

\section{A abordagem do problema por Pierre Bourdieu}

A crítica ao uso de materiais biográficos pode ser localizada em alguns momentos da produção escrita de Pierre Bourdieu. Para os fins deste estudo, circunscrevemos sua discussão em apenas três textos.

Inicialmente formulada no ensaio "A ilusão biográfica", a crítica se dirige à história de vida como a "história de uma vida", que se desenvolve de forma lógica e cronológica, no sentido de mostrar a vida como "conjunto de eventos de uma existência individual conhecido como uma história e relatado como uma história" ou

[...] um todo, um conjunto coerente e orientado, que pode e deve ser apreendido como expressão unitária de uma "intenção" objetiva e subjetiva de um projeto: a noção sartreana de "projeto original" coloca explicitamente o que está implicado nos "já”, "por conseguinte”, "desde a mais tenra idade", etc., de biografias ordinárias ou nos "sempre" ("sempre amei a música") das "histórias de vida”. (BOURDIEU, 1986, p. 69 , aspas do autor)

Critica, ainda, a tendência de se estabelecer conexões com os eventos, dando-lhes sentido e coerência, como sendo uma criação artificial de sentidos, nem sempre existentes nos acontecimentos em si. Para isso, contribuem as instituições de totalização e de unificação de si, como o nome próprio (a constância nominal) que só atesta a identidade de uma personalidade, como individualidade socialmente constituída, por uma 
formidável abstração; além de outros mecanismos, como o estado civil, o currículo vitae e a biografia oficial.

No bojo de sua análise, a história de vida pauta-se numa "sucessão longitudinal de eventos constitutivos da vida considerados como história em relação ao espaço social em que ocorre" que conduz a construção da "noção de trajetória como série de posições sucessivamente ocupadas por um mesmo agente (ou um mesmo grupo) num espaço em devir e sujeito a incessantes transformações" (BOURDIEU, 1986, p. 71, grifo do autor).

Para compreender uma trajetória, seria preciso conhecer os estados (aos menos os mais pertinentes) sucessivos do campo em que ela se desenvolve para estabelecer relações objetivas entre os agentes nesse mesmo campo e afrontados com o mesmo espaço de possíveis. Só assim se poderia descrever a personalidade designada pelo nome próprio, ou seja,

[...] "o conjunto de posições simultaneamente ocupadas num momento dado por uma individualidade biológica socialmente instituída como suporte de um conjunto de atributos e de atribuições que lhe são próprias e lhe permitem intervir como agente eficiente nos diferentes campos". (BOURDIEU, 1986, p. 72)

O que Bourdieu alcunhou como ilusão biográfica é uma espécie de ficção de si, apoiada em instituições de totalização e de unificação de si que direcionam a atribuiçãoo de sentidos e a busca de coerência aos acontecimentos considerados, pelo narrador, como mais significativos na história de sua vida. Em outras palavras, é a ilusão retrospectiva finalista de concatenação de fatos e acontecimentos cuja causalidade e implicação são construídos a posteriori, de acordo com o contexto de narração da história.

Vejamos agora como ele aprofunda essas reflexões em trabalhos posteriores. No livro As regras da arte, dedicado a analisar a gênese e a estrutura do campo literário francês a partir da figura do escritor Gustave Flaubert, Bourdieu retorna brevemente à discussão da ilusão biográfica denunciando a monstruosidade conceitual do "projeto original" sartreano, responsável por análises literárias que incorrem na ilusão 
retrospectiva, ou seja, na crença de que os autores estudados são dotados de um dom ou de uma predestinação que justificam suas vidas, organizadas como histórias que se desenrolam desde uma origem até um ponto final. A origem tem múltiplos sentidos: início, ponto de partida, causa primeira ou princípio gerador. Dela decorre a vida como um todo, um "conjunto coerente e orientado, e que só pode ser apreendida como a expressão unitária de uma intenção, subjetiva e objetiva, que se anuncia em todas as experiências, sobretudo as mais antigas" (BOURDIEU, 2005, p. 213).

No caso das análises do que chama de "personagens de exceção", como os artistas que são tomados como objeto de estudo, essa ilusão retrospectiva se mostra ainda mais forte pelo esforço dos biógrafos de atribuir vocações conforme uma lógica presente na linguagem comum, na qual:

[...] a vida é inseparavelmente o conjunto dos acontecimentos de uma existência individual concebida como uma história e um relato dessa história: ela descreve a vida como um caminho, uma carreira, com suas encruzilhadas e suas emboscadas, ou como uma caminhada, um caminho que se faz e que está por fazer, uma corrida, um cursus, uma viagem, um percurso, um deslocamento linear e unidirecional que comporta um começo ('uma estréia na vida'), etapas e um fim, no duplo sentido do termo e de objetivo ('ele fará seu caminho' significa: será bem-sucedido na vida), um fim da história. (BOURDIEU, 2005, p. 404, grifos do autor)

A primeira tentativa de um modo diferente de usar elementos autobiográficos como conteúdo de análise sociológica é encontrada no livro Meditações pascalianas, especificamente no "Pós-Escrito 1: Confissões impessoais", considerado como o embrião de Esboço de autoanálise (que, por sua complexidade, não será possível examinar neste trabalho e será objeto do próximo estudo). Elegendo minuciosamente alguns aspectos de sua trajetória acadêmica, o autor realiza um exercício de reflexividade no qual se abstém de "desfiar lembranças ditas pessoais que constituem a tela de fundo pardo das autobiografias universitárias, encontros maravilhados com mestres eminentes, escolhas intelectuais entrelaçadas a escolhas de carreira" (BOURDIEU, 2007, p. 44), ou seja, ainda que esteja a tratar sobre aspectos emanados de sua própria vida, ensaia uma fuga dos 
conteúdos que tradicionalmente são encontrados em materiais autobiográficos, que comumente se alinham a uma visão finalista.

Apreciando essas "Confissões impessoais" como parte de um livro que tem como objetivo refletir sobre os limites e os poderes do pensamento, assim como sobre as condições intelectualmente valorizadas de seu exercício, compreende-se melhor a afirmação de que

Aquele que se dá ao trabalho de romper com a complacência das evocações nostálgicas para explicitar a intimidade coletiva das experiências, das crenças e dos esquemas comuns de pensamento, ou seja, um pouco desse impensado que se encontra quase inevitavelmente ausente das mais sinceras autobiografias (material tão evidente que passa despercebido, ou então, recalcado como indigno de publicação quando aflora à consciência), expõe-se a ferir o narcisismo do leitor que se sente objetivado contra sua vontade, por procuração, e de maneira tanto mais cruel, paradoxalmente, por estar mais próximo, em sua pessoa social, do responsável por esse trabalho de objetivação. A menos que o efeito de catarse produzido pela tomada de consciência se exprima, como às vezes acontece, por um riso liberado e liberador. (BOURDIEU, 2007 p. 44-45)

Aqui, estamos diante de um novo nível de crítica ao material de natureza biográfica que resvala na relação com o público destinatário, determinada pela maneira de seleção, nem sempre consciente, daquilo que deve ser exposto. Ao longo da análise, o autor sinaliza que "apenas pelo fato de que nos fixamos em pensamento sobre nossa prática, que nos voltamos para ela para considerá-la, descrevê-la, analisá-la, tornamo-nos de certo modo ausentes, e tendemos a substituir agente atuante pelo 'sujeito' reflexivo, o conhecimento prático pelo conhecimento erudito" (BOURDIEU, 2007 p. 64, aspas do autor), num exercício de seleção dos fatos merecedores de exposição que demanda uma espécie de cisão entre o sujeito que vive e o sujeito que pensa sobre o vivido.

Esse conjunto de ideias, presentes nos três textos de Pierre Bourdieu, evidencia o valor das histórias de vida em sua obra. Elas são entendidas como construções narrativas que, geralmente, padecem da ilusão retrospectiva finalista ao apresentar uma história coerente, ordenada, cronologicamente organizada e logicamente adequada ao contexto presente. Essas observações alertam para os cuidados que os investigadores em geral 
devem ter diante desse tipo de material ao realizar suas pesquisas científicas. Como sociólogo, certamente suas críticas enfatizavam os perigos que ele e seus pares incorreriam ao desconsiderar a noção de trajetória frente aos relatos diacronicamente lineares que caracterizam as histórias de vida. Esses cuidados não invalidam, no entanto, o uso de material biográfico, do qual as histórias de vida respondem por apenas uma parcela.

\section{O que podemos aprender em L'illusion biographique?}

Mesmo não explicitando no corpo desta análise os textos que não apresentam reflexões teóricas sobre o método biográfico, ainda que o utilize, este estudo tem como primeiro aprendizado algo demasiadamente óbvio: uma edição que reúne mais de uma dezena de textos, agrupados sob um título polêmico, não pode cometer a indelicadeza de deslegitimar seus colaboradores. Dito de outro modo, se a Actes acolheu trabalhos que utilizam o método biográfico e a eles dedicou uma edição exclusiva, seria cientificamente incoerente e editorialmente inconsequente o fato de seu diretor publicar um ensaio que afrontasse a pertinência dos textos que ele mesmo selecionou para veiculação.

Desfazer a imagem de Pierre Bourdieu como um intelectual absolutamente refratário ao método (auto)biográfico já seria um achado de grande importância para um estudo tão limitado. No entanto, há, ainda, outros aprendizados que podemos extrair desta incursão em L'illusion biographique.

O primeiro diz respeito à heterogeneidade de opiniões sobre o alcance e a finalidade da metodologia (auto)biográfica, evidenciada na diversidade de propostas analisadas. Pollack sugere o uso de material, fundamentalmente obtido por meio de entrevistas com os próprios sujeitos investigados, para a construção de modelos de explicação, pautados em histórias individuais, sobre um mesmo tipo de experiência. Becker apresenta uma forma mais ampliada de coleta (que não se basta com relatos dos próprios sujeitos, mas que exige outras fontes documentais e narrativas) para formular conhecimentos científicos sobre instituições, regiões e outros coletivos sociais que colaborem com uma teoria geral da sociologia. Embora apresentem formas diversificadas 
de trabalho, não há contradições entre os autores acerca do potencial científico do método (auto)biográfico. Cada qual sugere as formas de uso mais adequadas para os seus objetos de pesquisa, o que confirma o princípio científico de que cada tipo de objeto demanda certo tipo de tratamento metodológico. Contrapor os autores, assim como contrapô-los ao posicionamento de Bourdieu, seria um contrassenso que demonstraria a ausência de percepção sobre as especificidades de suas práticas científicas.

Aprendemos, ainda, que um trabalho de natureza biográfica não se restringe à coleta de relatos, entrevistas, depoimentos etc. fornecidos diretamente pelos sujeitos envolvidos no objeto estudado. Ele deve incluir outros tipos de informações que adensem a história destinada à especulação sociológica. Nisso, há absoluto consenso entre os colaboradores da edição, atestado pela pluralidade de fontes expostas.

E para confirmar a hipótese que motivou este estudo, o uso da noção de trajetória como alternativa para apreensão dos sentidos expressos em narrativas e demais documentos biográficos, comparemos a metáfora do funcionamento do metrô, presente no artigo de Pierre Bourdieu, com algumas ideias presentes nos demais.

Para Bourdieu, a vida de um indivíduo não pode ser narrada linearmente, sem considerar as relações com distintos agentes em diferentes campos ao longo de sua existência, tal como o funcionamento de uma determinada linha do metrô não pode ser avaliado apenas pelo que acontece em seu trajeto, que é variavelmente influenciado pelos acontecimentos nas linhas que a entrecruzam. Talvez a imagem não faça muito sentido quando temos em mente as apoucadas malhas ferroviárias das principais cidades brasileiras, mas ainda assim permite imaginar, tal como no caso do metrô de Paris, a trajetória de uma vida como algo extremamente complexo, multifacetado, rizomático, impossível de ser explicitado num discurso cronologicamente ordenado e linearmente concluído.

Com outras palavras, Pollack e Becker nos mostram que uma análise científica na perspectiva biográfica deve integrar elementos que sirvam de comprovação das narrativas, fazendo da triangulação de dados um procedimento de garantia da legitimidade dos resultados, ainda que não sejam definitivos. Nesse sentido, o diálogo constante entre o trabalho empírico e a reflexão teórica é indicado como postura fundamental ao pesquisador para que as histórias de vida possam ser vistas como indícios 
de uma determinada história social individual, condicionadas por e reveladoras de seus contextos de produção, sempre consideradas como reconstruções a posteriori dos acontecimentos mais significativos que marcaram uma trajetória.

Ciente de que o debate sobre o valor das histórias de vida na sociologia de Bourdieu não se esgota neste trabalho e que o crescimento da produção na perspectiva autobiográfica poderá reunir muitos outros elementos para a reflexão sobre essa aparente polêmica, tomo de empréstimo as palavras conclusivas de Becker, escritas há quase meio século, para afirmar a expectativa de que "[...] uma melhor compreensão da complexidade da demarcação científica restitua aos sociólogos o sentido do valor e das múltiplas vantagens do método biográfico [...] em novas direções que restam definir" (BECKER, 1986, p. 110).

\section{Referências}

BALAZS, Gabrielle; FAGUER, Jean-Pierre. Un conseil de classe très particulier. Actes de la Recherche en Sciences Sociales. v. 62-63, p. 115-117, jun., 1986.

BECKER, Howard. Biographie et mosaïque scientifique. Actes de la Recherche en Sciences Sociales. v. 62-63, ju., p. 105-110, 1986.

BOURDIEU, Pierre. L'illusion biographique. Actes de la Recherche en Sciences Sociales. v. 62-63, jun., p. 69-72, 1986.

BOURDIEU, Pierre. As regras da arte: gênese e estrutura do campo literário. 2. ed. São Paulo: Companhia das Letras, 2005.

BOURDIEU, Pierre. Meditações pascalianas. 2. ed. Rio de Janeiro: Bertrand Brasil, 2007. 
CARLOTTI, François. In memoriam. Actes de la Recherche en Sciences Sociales. v. 62-63, p. 111-114, jun., 1986.

ENCREVÉ, Pierre. Fils de pasteur ou enfants de pasteur(s). Actes de la Recherche en Sciences sociales. v. 62-63, p. 81-83, jun., 1986.

HAHN, Alois. Contribution à la sociologie de la confession et autres formes institutionnalisées d'aveu. Actes de la Recherche en Sciences Sociales. v. 62-63, p. 54-68, jun., 1986.

MUEL-DREYFUS, Francine; MARTINS, Arakcy. Réincarnations. Actes de la Recherche en Sciences Sociales. v. 62-63, p. 118-134, jun., 1986.

PÉNISSON, Pierre. Fils de pasteur. Actes de la Recherche en Sciences Sociales. v. 62-63, p. 73-80, jun 1986.

PINÇON, Michel; RENDU, Paul. Un ouvrier désenchanté. Actes de la Recherche en Sciences Sociales. v. 62-63, p. 93-99, jun., 1986.

PINELL, Patrice. Le paradis perdu. Actes de la Recherche en Sciences Sociales. v. 62-63, p. 100-104, jun., 1986.

POLLACK, Michael; HEINICH, Nathalie. Le témoignage. Actes de la Recherche en Sciences Sociales. v.62-63, p.3-29, jun., 1986.

POLLACK, Michael. La gestion de l'indicible. Actes de la Recherche en Sciences Sociales. v. 62-63, p. 30-53, jun., 1986.

ZARCA, Bernard. La vie militante d'un peintre en lettres. Actes de la Recherche en Sciences Sociales. v. 62-63, p.83-92, jun., 1986. 